\title{
Estudo da qualidade socioambiental urbana dos distritos do Murucupi e Vila do Conde em Barcarena Pará com uso de indicadores ambientais urbanos
}

A expansão urbana na Amazônia, no último meio século, é resultado da implantação programada de Grandes Empreendimentos Industriais. Esse modelo de desenvolvimento em novos espaços produtivos integrados à modernidade global causou efeitos sociais e ambientais adversos. A cidade de Barcarena enquanto ambiente urbano amazônico é um espelho deste cenário contraditório entre desenvolvimento e impactos socioambientais. O objetivo desse estudo é descrever, expressar e analisar a qualidade ambiental do entorno do Bairro Industrial de Barcarena, correspondente aos Distritos do Murucupi e Vila do Conde, utilizandose como metodologia indicadora de qualidade ambiental urbana. Os dados coletados serviram para interpretar as variáveis causadoras dos impactos socioambientais no entorno urbano-industrial dos Grandes Empreendimentos em Barcarena. Os resultados dos indicadores de abastecimento de água 3,6 pontos, esgotamento sanitário 4,8 pontos, coleta de resíduos sólidos 19,6 pontos, pavimentação de vias, 7,5 pontos e cobertura vegetal 9,3 pontos; ao serem agregados apontam para um índice de qualidade ambiental ruim, 44,8 pontos, posto que a pontuação máxima do índice proposto seja 100 pontos. A pontuação 44,8 do índice de qualidade ambiental expressa no seu conjunto às condições socioambientais insalubres pela negação do acesso ao abastecimento de água potável, ao esgotamento sanitário, coleta de resíduos sólidos, a pavimentação de vias a cobertura vegetal, direitos essenciais às populações residentes desse recorte territorial urbano, com risco iminente a sua qualidade de vida e comprometimento à sua saúde.

Palavras-chave: Barcarena; Qualidade Socioambiental; Grandes Empreendimentos.

\section{Study of urban environmental quality of the districts Murucupi and Vila do Conde in Barcarena Pará with the use urban indicators' environment}

\begin{abstract}
The urban expansion in the Amazon, in the last half century, is the result of the planned implantation of Large Industrial Enterprises. This development model in new productive spaces integrated with global modernity has caused adverse social and environmental effects. The city's Barcarena, as a space urban Amazonian, is a mirror of this contradictory scenario, between development and socioenvironmental impacts. The objective of this study is to describe, express and analyze the environmental quality of the Districts Barcarena Industrial, corresponding to the Murucupi and Vila do Conde Districts, using urban environmental quality indicators as methodology. The collected data were used to interpret the variables that cause socio-environmental impacts in the urban-industrial environment of the Large Enterprises in Barcarena. The results of the water supply indicators 3.6 points, sanitary sewage, 4.8 points, collection of solid waste 19.6 , paving of roads, 7.5 and vegetation cover, 9.3; and when aggregated, they point to a bad environmental quality index, 44.8 points, since the maximum score of the proposed index corresponds to 100 points. The score of 44.8 points of the environmental quality index expressed as a whole to the unhealthy socioenvironmental conditions is the denial of access to drinking water supply, sanitation, the paving of roads and vegetation cover, essential rights for the residents of this territorial area urban, with imminent risk to their quality of life and compromise to their health.
\end{abstract}

Keywords: Barcarena; Socio Environmental Quality; Great Enterprises.

Topic: Desenvolvimento, Sustentabilidade e Meio Ambiente

Reviewed anonymously in the process of blind peer.

Francisco Assis Melo

Universidade Federal do Pará, Brasil

ssaisemelo@yahoo.com.br

Márcia Aparecida da Silva Pimentel (iD)

Universidade Federal do Pará, Brasil

http://lattes.cnpq.br/3994635795557609

http://orcid.org/0000-0001-9893-9777

mapimentel@ufpa.br

Tabilla Verena da Silva Leite

Universidade Federal Rural da Amazônia, Brasil

http://lattes.cnpq.br/2987946613625343

verenatabila@gmail.com

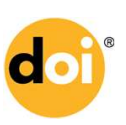

DOI: 10.6008/CBPC2179-6858.2021.005.0045
Received: 22/04/2021

Approved: 23/05/2021
Referencing this:

MELO, F. A.; PIMENTEL, M. A. S.; LEITE, T. V. S.. Estudo da qualidade socioambiental urbana dos distritos do Murucupi e Vila do Conde em Barcarena Pará com uso de indicadores ambientais urbanos. Revista Ibero Americana de Ciências Ambientais, v.12, n.5, p.565-586, 2021. DOI: http://doi.org/10.6008/CBPC2179-6858.2021.005.0045 


\section{INTRODUÇÃO}

A cidade de Barcarena tem origem nas missões jesuítas, no século XVII, e permaneceu como extensão rural de Belém até 1943, ano em que se emancipou por meio do Decreto Lei 4.505/1943, que a elevou a condição de Município. Entre os anos de 1946 e 1960 houve a transferência da sua sede administrativa da vila de São Francisco para a margem esquerda do rio Mucuruçá. Entre 1960 e 1980, a nova sede de Barcarena situada às margens do rio Mucuruçá, se tornou um importante polo irradiador da população no município de Barcarena (COSTA et al., 2018). Neste período a feição socioespacial de Barcarena sofreu profundas modificações provocadas pela chegada de investimentos internacionais programados pelo Estado brasileiro.

A expansão do capital internacional trouxe consigo o processo de implantação do Complexo Industrial em Barcarena, entre as décadas de 1970 e 1980, que alterou profundamente a configuração do espaço e da população, provocando uma série de mudanças decorrentes das políticas de inserção da Amazônia no contexto do mercado econômico mundial e por outro, ligado aos interesses dos governos brasileiros e estrangeiros promoveram um reordenamento das terras do município de Barcarena para a implantação do grande projeto industrial minero-metalúrgico (MPF, 2018). A economia de Barcarena se tornou polarizada pelo complexo industrial alumina-alumínio da Albrás e Alunorte, sendo complementada pela atividade portuária projetada para servi-la no Parque Portuário de Vila do Conde. Dentro do setor primário, destaca-se a atividade agropecuária, além de avançar no setor terciário com o turismo e serviços, gerando um controverso crescimento econômico para o município e para o Estado do Pará, visto que a horizontalidade do capital neste município é acompanhada das mazelas dos impactos socioambientais.

A intensa atividade industrial em Barcarena estabelece uma ordem socioambiental perigosa marcada pela escalada dos impactos ambientais, próprios das áreas de entorno industrial; bem como a ocorrência sucessiva de desastres ambientais ao longo de trinta e quatro anos de funcionamento do complexo minero-metalúrgico, e comprometem a biodiversidade aquática e terrestre, a atmosfera, as populações urbanas e as comunidades tradicionais que se encontram na vizinhança desse empreendimento industrial (MARIN et al., 2015).

O quadro socioambiental adverso que predomina em Barcarena impõe o desafio de estudos que possam descrever, mensurar e analisar os problemas socioambientais resultantes da atividade industrial e das demais atividades conexas a esse padrão de produção neste recorte territorial urbano amazônico. E este trabalho se propõe a descrição e análise das variáveis da qualidade socioambiental do entorno industrial dos empreendimentos em Barcarena, em específico os Distritos do Murucupi e Vila do Conde, com o uso de indicadores que possam expressar a qualidade do ambiente intraurbano dessa cidade amazônica, e desta forma abrir caminhos para a proposição de mitigações dos impactos socioambientais que flagelam, principalmente, as parcelas socioambientalmente mais vulneráveis da população de Barcarena. 
Estudo da qualidade socioambiental urbana dos distritos do Murucupi e Vila do Conde em Barcarena Pará com uso de indicadores ambientais urbanos

\section{METODOLOGIA}

“" A cidade de Barcarena-Pará pertencente à mesorregião Metropolitana de Belém e se localiza-se

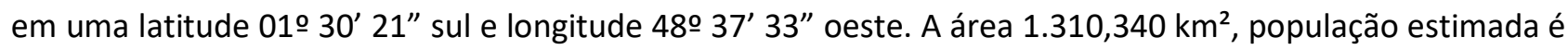
127.027 habitantes, clima quente e úmido, ocorrência de precipitação durante todo o ano sem variação sensível entre as estações, proporcionando muita instabilidade atmosférica, com forte convecção e precipitação. A vegetação do município é predominantemente constituída por: floresta densa; vegetação de várzea e por florestas secundárias. A cobertura vegetal primitiva de floresta densa foi quase totalmente substituída pela ação dos desmatamentos para o plantio de espécies agrícolas de subsistência e pequenos pastos, e em certas áreas permitindo-se o pousio houve a regeneração florestal com diferentes estágios de desenvolvimento da floresta secundária. Ao longo das margens dos rios e igarapés, preponderam as florestas ciliares e de várzeas nos trechos sob influência de inundações, ocorrendo, também, o mangue e a siriúba, margeando os grandes rios e as ilhas do município (PARÁ, 2011; IBGE, 2020).

Estabelecemos um lócus de referência ou área de abordagem georreferenciada no entorno imediato dos grandes empreendimentos correspondente ao Bairro Industrial de Barcarena que está subdivido em Distrito do Murucupi e Distrito de Vila do Conde, que correspondem à área de estudo descrita na Figura 1.

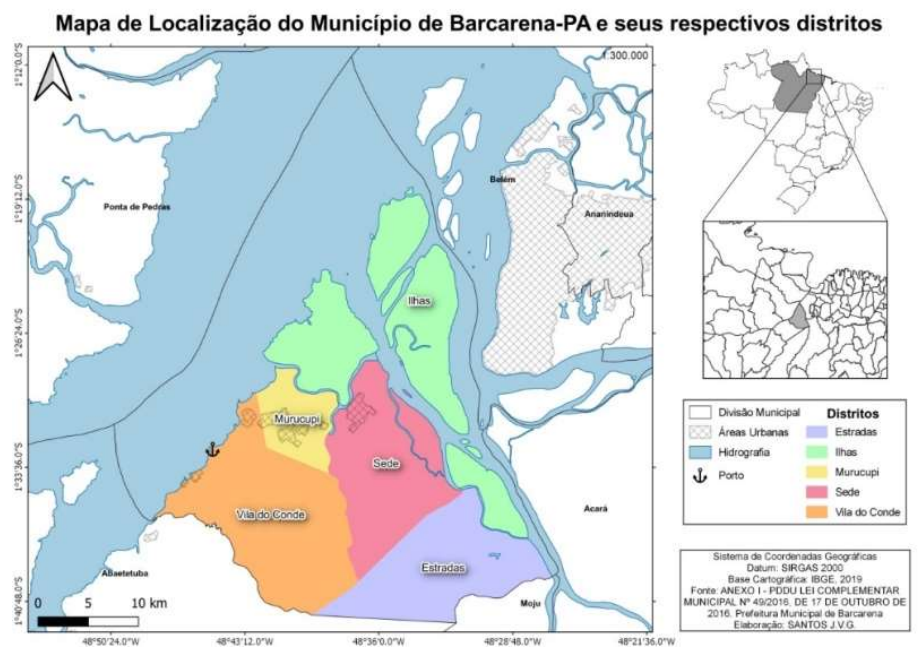

Figura 1: Localização do Município de Barcarena com Indicação da Área de Estudo. Fonte: IBGE

Selecionou-se essa área de estudo por ser a mais afetada com a expansão urbano-industrial de Barcarena, pois localiza-se no entorno imediato dos grandes empreendimentos minero-metalúrgico e portuário, e sofre com os impactos e desastres ambientais que repercutem como alerta para os riscos de certos empreendimentos industriais em ambientes vulneráveis à ação humana na Amazônia; havendo registros de desastres ambientais de múltiplas naturezas nos últimos 20 anos: derramamento de produtos químicos, episódios de vazamento de lama vermelha das bacias de rejeito da Alunorte, chuva de fuligem, floração de algas, vazamento de óleo, rompimento de duto com efluentes ácidos, naufrágio de embarcação com centenas de bois vivos (SANTOS, 2015; MARTINS, 2015; CRISTO et al., 2018; SILVA, HAZEU, 2019).

A delimitação dessa área respeita certas características relacionadas aos setores censitários com características homogêneas, em diferentes escalas, os quais aparecem como manchas ou retalhos e variam 
Estudo da qualidade socioambiental urbana dos distritos do Murucupi e Vila do Conde em Barcarena Pará com uso de indicadores ambientais urbanos

MELO, F. A.; PIMENTEL, M. A. S.; LEITE, T. V. S.

de tamanho, forma, tipo, heterogeneidade e características de bordas, permitindo a confiabilidade no uso de instrumentais metodológicos e por conseguinte uma maior solidez e veracidade nos resultados obtidos (MAGALHÃES JÚNIOR, 2012).

Os dados de precipitação utilizados nesta pesquisa pertencem ao banco de dados CHIRPS-Climate Hazards Group InfraRed Precipitation with Stations, que consiste em uma de dados formada por diversas fontes de informações, que são: (I) The Climate Hazards Group's Precipitation Climatology (CHPClim); (II) Observações de satélites com espectroscopia de infravermelho termal (Thermal Infrared, TIR), geoestacionárias quase globais da National Oceanic and Atmospheric Administration (NOAA), Centro de Previsão Climática (CPC) e o National Climatic Data Center Climáticos (NCDC); (III) Campos de Precipitação do Coupled Forecast System da NOAA, versão 2 (CFSv2); (IV) Diversas observações de precipitação através de produtos de estações meteorológicas e outros serviços regionais (FUNK et al., 2015). A principal característica desse conjunto de dados está na altíssima resolução espacial de aproximadamente $5 \mathrm{~km}$, próximo ao equador, cobertura geográfica global de 50 ㅇ S a 50 N, com o período de dados iniciando em 1981 e se estendendo até os dias atuais, sendo disponibilizado em UCSB ${ }^{1}$, em formato NetCDF, GeoTiff e Esri BIL, nas resoluções temporais diários, pêntadais e dados mensais.

Os dados de temperatura do ar (máxima, mínima e média) foram obtidos junto ao European Centre for Medium Range Weather Forecast Reanalysis (Era5) que pertecence ao European Centre for Medium Range Weather Forecasts (ECMWF). O ERA5 fornece estimativas de hora em hora de um grande número de variáveis climáticas atmosféricas, terrestres e oceânicas. Os dados cobrem a Terra em uma grade de $30 \mathrm{~km}$ e resolvem a atmosfera usando 137 níveis da superfície até uma altura de $80 \mathrm{~km}$. Os dados de temperatura do ar e umidade relativa utilizados nesta pesquisa possuem resolução temporal horária (a cada 3 horas) e resolução espacial de 0,25 (aproximadamente $27 \mathrm{~km}$ ), compreendo o período de 1985 a 2020 . Os dados foram utilizados para o cálculo de anomalias em períodos de 5 e 10 anos. Os dados do Era5/ECMWF são públicos².

O estudo proposto se baseia na modelagem do índice de qualidade ambiental urbana desenvolvido por Dias (2011), pois a agregação de indicadores possibilita uma análise integrada da realidade nas suas diversas configurações socioespaciais e ambientais (MELO; UENO, 2013). Os indicadores de qualidade ambiental foram estruturados objetivando identificar os níveis satisfatórios e os níveis críticos do ambiente intraurbano do Bairro Industrial de Barcarena, que está delimitado pelos Distritos do Murucupi e Vila do conde. Fez-se a escolha dos indicadores, julgando-se que atendem a proposta deste estudo, visto agregarem variáveis que compõem os indicadores ambientais, a fim de apresentar de forma organizada a descrição e análise dos resultados obtidos que sintetizam a qualidade ambiental das áreas intraurbanas analisadas (DIAS, 2011; MELO et al., 2013). O Índice de Qualidade Ambiental Urbana (IQAU) estruturado por Dias (2011) é especificado conforme ilustra o Quadro 1.

Quadro 1: Descrição do Índice de Qualidade Ambiental Urbana.

\footnotetext{
${ }^{1} \mathrm{ftp}: / / \mathrm{ftp} . c h g . u c s b . e d u / p u b / o r g / c h g / p r o d u c t s / C H I R P S-2.0 /$

${ }^{2}$ https://www.ecmwf.int/en/forecasts/datasets/reanalysis-datasets/era5/ 


\begin{tabular}{|c|c|c|c|c|c|}
\hline Indicadores & Cálculos dos Indicadores & $\begin{array}{l}\text { Índices } \\
\text { parciais }\end{array}$ & $\begin{array}{l}\text { Peso dos } \\
\text { Indicadores }\end{array}$ & $\begin{array}{c}\text { Composição } \\
\text { dos } \\
\text { Indicadores }\end{array}$ & IQAU \\
\hline $\begin{array}{l}\text { Abastecimento de água } \\
\qquad(I a b s)\end{array}$ & $I a b s=\left(\frac{n}{t}\right)$ & $0-1$ & 15 & & \\
\hline $\begin{array}{l}\text { Esgotamento sanitário } \\
\text { (Ies) }\end{array}$ & Ies $=\frac{p 1 t 1+p 2 t 2+\cdots p n t n}{p 1+p 2+}$ & $0-1$ & 35 & IQAU= & \\
\hline $\begin{array}{l}\text { Limpeza pública urbana } \\
\text { (Ilpu) }\end{array}$ & $I l p u=\left(\frac{D a}{T d}\right)$ & $0-1$ & 20 & $\begin{array}{l}l a P a+l b P b+l c P \\
c+l d P d+l e P e\end{array}$ & 100 \\
\hline $\begin{array}{l}\text { Pavimentação das ruas } \\
\text { (Ipav) }\end{array}$ & $\operatorname{Ipav}=\left(\frac{\operatorname{Lpav}}{\text { Ltotal }}\right)$ & $0-1$ & 15 & & \\
\hline $\begin{array}{c}\text { Cobertura Vegetal } \\
\text { (Icv) }\end{array}$ & $I c v=\left(\frac{\text { Aveg }}{\text { Atotal }}\right)$ & $0-1$ & 15 & & \\
\hline
\end{tabular}

Os índices parciais, na terceira coluna, são números que expressam o estado do indicador avaliado, podendo variar de zero a um. Um indicador cujo índice obtido é zero corresponde à pior avaliação possível enquanto o índice 1 (um) é aplicado a melhor avaliação. $O$ índice de qualidade ambiental urbana, coluna 6 do quadro 1, resulta da soma dos indicadores parciais correspondentes multiplicados pelo seu respectivo peso.

Onde: $\mathrm{a}, \mathrm{b}, \mathrm{c} . .$. indicadores parciais; Atotal: Área total $\left(\mathrm{km}^{2}\right) ;$ Aveg: Área coberta por vegetação $\left(\mathrm{km}^{2}\right)$; $D a$ : domicílios atendidos pelo serviço de coleta de lixo (\%); I: índice parcial; Lpav: extensão de vias pavimentadas (km); Ltotal: total de vias (com e sem asfaltamento); $n$ : número de domicílios ligados à rede de abastecimento (\%); P: peso do respectivo índice parcial; pn: Fator de peso atribuído para o tipo de disposição do esgoto de acordo com o Quadro 4 apresenta o tipo de disposição dos esgotos e o seu peso no Ies.; $t$ : número total de domicílios (\%); $T d$ : total de domicílios (\%); tn: Porcentagem do tipo de disposição/afastamento do domicílio.

Quadro 2: Formas de disposição/afastamento dos esgotos e o respectivo peso de cada uma na avaliação da qualidade ambiental.

\begin{tabular}{lc}
\multicolumn{1}{c}{ Forma de disposição/afastamento dos esgotos } & Peso \\
Rede de esgoto com tratamento posterior & 1,0 \\
Rede de esgotos ou drenagem sem tratamento posterior & 0,5 \\
Fossa séptica com sumidouro ou ligada à drenagem & 0,4 \\
Fossa rudimentar & 0,2 \\
Vala de infiltração ou outro escoadouro & 0,1 \\
Sem dispositivo de afastamento & 0,0
\end{tabular}

Fonte: Dias (2011).

O índice de esgotamento sanitário resulta do somatório das médias ponderadas para cada tipo de disposição. O sistema de pontuação do Índice de Qualidade Ambiental é descrito no Quadro 3.

Quadro 3: Pontuação do Índice de qualidade ambiental urbana

\begin{tabular}{|ccc|}
\hline Classe de IQAU & Valor do IQAU & Nível de qualidade \\
A & $85-100$ & Ótimo \\
B & $65-85$ & Bom \\
C & $50-65$ & Intermediário (Regular) \\
D & $25-50$ & Ruim \\
E & $0-25$ & Péssimo \\
\hline
\end{tabular}

Fonte: DIAS (2011). 
O mapa de cálculo das vias foi confeccionado com arquivos vetoriais (shapefiles) da base cartográfica contínua do IBGE do ano de $2019^{3}$ e mais arquivo vetorial criado manualmente a partir da vetorização de um mapa base da prefeitura de Barcarena contendo os limites dos distritos que compõem o município. Todos os arquivos estão no Datum SIRGAS 2000. A vias foram vetorizadas manualmente a partir de uma imagem de satélite da base do Google, adquirida por meio do plugin do QGIS Quick Map Services.

Mapa das áreas de risco nas vias: o arquivo vetorial (.shp) criado para das áreas de risco foi feito a partir da análise de imagens contendo os limites das áreas de riscos mapeadas dentro do software Google Earth Pro pela prefeitura municipal de Barcarena. O mapa gerado foi feito a partir dos shapefiles criados previamente para os demais mapas mais o novo das áreas de risco, acrescentando também a tabela com as identificações de cada uma das onze áreas de riscos presentes na área de estudo. Para classificação de uso e cobertura do solo foi utilizado o satélite de referência Sentinel $2 \mathrm{~A}$, possuindo resolução espacial de 10 metros para o dia 25/05/2020, sendo obtida através da plataforma do Serviço Geológico dos Estados Unidos (USGS). O processamento foi realizado a partir do software de processamento digital de imagens Envi 5.3, onde foi realizado a coleta de amostras para cada classe encontrada, obtendo um total 7 classes, sendo 40 amostras para da classe.

O método de classificação foi realizado a partir do estimado de Máxima verossimilhança, no qual as classes coletadas seguem uma distribuição normal multivariada onde a reorganização de pixels é feita por métodos probabilísticos (NISHIDA et al., 1998). As classes resultantes do processo são descritas abaixo.

Quadro 4: Características das classes de uso e cobertura da terra

\begin{tabular}{|l|l|}
\hline \multicolumn{1}{|c|}{ Classe } & \multicolumn{1}{c}{ Características } \\
\hline Vegetação Densa & $\begin{array}{l}\text { Área florestal, geralmente primária, no qual possuem indivíduos emergentes de grande porte formando um extenso } \\
\text { dossel. }\end{array}$ \\
\hline $\begin{array}{l}\text { Vegetação } \\
\text { Secundária }\end{array}$ & $\begin{array}{l}\text { Áreas geralmente alteradas, após a supressão total ou parcial da vegetação florestal, encontrando-se em processo } \\
\text { avançado de regeneração. }\end{array}$ \\
\hline Vegetação Rasteira & $\begin{array}{l}\text { Áreas com vegetação pouco desenvolvidas ou áreas com sofreram supressão total da vegetação, sendo convertidas em } \\
\text { pastos ou agricultura. }\end{array}$ \\
\hline Hidrografia & Águas superficiais que formam espelhos d'água. \\
\hline Área Estruturada & $\begin{array}{l}\text { Áreas residenciais, comerciais e industriais, com edificações e construções (pontes, calçadas e etc.), vias pavimentadas e } \\
\text { não pavimentadas. Áreas de solo exposto. }\end{array}$ \\
\hline Mineração & Área destinada à exploração mineral \\
\hline Massas D’agua & Águas superficiais que formam espelhos d'água. \\
\hline Nuvens & Conjunto de partículas de gelo ou água em suspensão em virtude de processos atmosféricos. \\
\hline Sombra de Nuvens & Sombra referente à Nuvem em suspensão, gerando uma penumbra no objeto imageado. \\
\hline
\end{tabular}

A avaliação da veracidade dos mapeamentos foi realizada a partir da ferramenta "Confusion Matrix Using Ground Truth ROIs" no qual gera a matriz de confusão das amostras a partir das classes identificadas, gerando o índice de Kappa. O Índice Kappa é um coeficiente de concordância que indica o quão legítimo são as interpretações, este coeficiente é calculado com base em uma matriz de confusão e, é utilizado como medida de concordância entre o mapa e a referência adotada para a estimativa da exatidão (COHEN, 1960). O Índice Kappa é expresso por:

$$
\mathrm{K}=\frac{P_{0}-P_{c}}{1-P_{c}}
$$

Em que: $P 0$ é a exatidão global; $P c$ é a proporção de unidades que concordam por casualidade.

${ }^{3}$ https://portaldemapas.ibge.gov.br/portal. php\#mapa222602 
Estudo da qualidade socioambiental urbana dos distritos do Murucupi e Vila do Conde em Barcarena Pará com uso de indicadores ambientais urbanos

MELO, F. A.; PIMENTEL, M. A. S.; LEITE, T. V. S.

A partir dos resultados, Landis e Koch (1977) associam valores do Índice Kappa à qualidade da classificação de acordo com a Tabela 1.

Tabela 1: Qualidade da classificação associada aos valores do Índice Kappa

\begin{tabular}{cc}
\hline Valores do Índice Kappa & Qualidade da Classificação \\
\hline 0,00 & Péssima \\
0,01 a 0,20 & Ruim \\
0,21 a 0,40 & Razoável \\
0,41 a 0,60 & Boa \\
0,61 a 0,80 & Muito Boa \\
0,81 a 1,00 & Excelente \\
\hline
\end{tabular}

Fonte: Landis et al. (1977).

Para a quantificação e representação espacial, utilizou-se um software de Sistema de Informação Geográfica (SIG), onde a classificação foi reclassificada e convertida em arquivo vetorial. Para a quantificação do arquivo vetorial, foi necessário a realização da reprojeção do sistema de referência, no qual era WGS84, sendo convertido em um sistema de referência métrico, Sirgas 2000 UTM Zona 22 S, podendo assim fazer o cálculo do arquivo vetorial, resultando uma planilha Excel contendo as quantificações e um mapa, especializando a área de análise.

O mapa da área de cobertura de coleta e tratamento de esgoto foi feita a delimitação da área urbanizada dentro dos limites dos distritos de Murucupi e Vila do Conde, através do processo de vetorização de um polígono sobre a imagem de satélite do Google Earth Pro (data das imagens: 9/8/2019). Após isso, o arquivo foi salvo em . $\mathrm{kml}$ e aberto dentro do QGis, onde foi transformado em shapefile (.shp). Dentro do ambiente do QGis, foi criado outro vetor de polígono demarcando a área do limite da Vila do Conde, a área originalmente planejada para ser a vila operária do complexo industrial de Barcarena. Essa área possui coleta e tratamento de esgoto desde sua fundação e a capacidade do sistema foi recentemente ampliada com a nova ETE (estação de tratamento de esgoto) localizada próximo ao rio Murucupi.

Foi utilizada a ferramenta "diferença simétrica" onde foi feito um recorte da área total menos a da Vila do Conde, resultando, assim, na área que não tem cobertura da rede de coleta e tratamento de esgoto do presente estudo. Posteriormente, foram acrescentadas simbologias para esses arquivos gerados, além de acrescentar outros shapefiles (arquivos vetoriais) contendo informações de hidrografia, rodovias e toponímias para a elaboração do mapa final.

Aquisição das informações censitárias e elaboração do banco de dados sobre abastecimento de água limpeza pública e esgotamento sanitários desenvolveram-se com a obtenção e armazenamento de informações do Censo demográfico de 2010/IBGE e Relatórios Técnicos das Secretarias Municipais de Barcarena. Foram realizadas coletas de dados primários através de visitas permanentes de campo para mensurar as variáveis que produziram os indicadores de qualidade ambiental (SERVA et al., 1995).

\section{RESULTADOS DISCUSSÃO}

Neste tópico se dispõe a descrição e quantificação dos indicadores que traçam a qualidade ambiental dos distritos do Murucupi e Vila do Conde, que estão no entorno industrial de Barcarena, com 
vistas a sua espacialização e melhor exposição das variáveis capazes de demonstrar os problemas socioambientais verificados nesta mancha urbana amazônica, fazendo-se a descrição ordenada dos resultados de cada indicador a seguir.

O Sistema de Abastecimento de água do município de Barcarena são sistemas independentes e não são interligados, os sistemas são compostos por Barcarena Sede, Pioneiro, Vila do Conde, Arapari, São Francisco, Vila do Cafezal, Nossa Senhora De Nazaré, Bairro Industrial, Vila Dos Cabanos, Itupanema, Residencial Cabano I e II, Vila Nova, Laranjal, Novo Horizonte. O município de Barcarena é abastecido pela rede pública, por poços escavados, artesianos e tubulares, além de igarapés (BARCARENA, 2013). A principal forma de abastecimento de água de Barcarena é feita por poços, com de $64 \%$ de predominância (INFOSANBAS-IBGE, 2020). Isso ocorre porque a população do entorno industrial não tem segurança na qualidade da água fornecida pela Concessionária que presta este serviço, além do que os moradores consideram o metro cúbico da água com valor muito elevado.

O abastecimento através da rede geral é de $24 \%$ e outra forma de abastecimento de água é de $12 \%$ (INFOSANBAS-IBGE, 2020). Os poços são denominados amazonas pela população local, sendo poços tubulares, quase sempre freáticos, com média de profundidade de 18 a $20 \mathrm{~m}$, o que impõem riscos à saúde humana, pois não dispõem de avaliação bioquímica e são perfurados em área de risco de contaminação (BRASIL, 2006). A equação do índice abastecimento de água aplicada ao percentual estimado em $24 \%$ dos domicílios atendidos pelo serviço de água da rede geral obteve-se o labs de 0,24 ponto. Neste indicador não foi considerada a qualidade da água servida à população.

Existem múltiplos riscos à saúde humana quando a população não tem acesso à água potável destinada à ingestão, preparação e produção de alimentos e à higiene pessoal, independentemente da sua origem, posto que a água tratada seja submetida a processos físicos, químicos ou combinação destes, visando atender ao padrão de potabilidade (BRASIL, 2011). OS riscos que a população enfrenta ao não ter acesso ao sistema de água tratada são: diarreia por Escherichia coli, disenteria bacteriana, Febre Tifóide, cólera, leptospirose, hepatite A, verminoses, arboviroses (dengue, Zika, Chikungunya e Febre Amarela), Amebíase intestinal, Giardíase (BRASIL, 2006). E se não tratadas adequadamente podem levar a óbito.

Em Barcarena no ano de 2017 foram registrados o total de 22 óbitos causados doenças infecciosas e parasitárias (IBGE, 2020). O Ministério da Saúde (MS, 2010) alerta que essas doenças podem em sua maioria ser causadas por veiculação hídrica, estando associadas à precariedade no sistema de abastecimento de água. Portanto são elevados os riscos que a população dos Distritos do Murucupi e Vila do Conde está sujeita ao acometimento de doenças infecciosas e contagiosas provocadas pela ausência de acesso ao sistema de abastecimento de água.

Marinho et al (2016) apontam que houve uma redução na ocorrência de casos e de óbitos relacionados às doenças infecciosas e parasitárias (DIP) de veiculação hídrica no período de 2008 a 2012, em Barcarena. No total, foram registrados 75 casos no município nesse período. As internações por DIP em Barcarena no mesmo período representaram 0,8\% dos casos em todo o Estado. Portanto mesmo que não haja abrangência aceitável do sistema de água potável para a população habitante de Barcarena, esta 
Estudo da qualidade socioambiental urbana dos distritos do Murucupi e Vila do Conde em Barcarena Pará com uso de indicadores ambientais urbanos

variável crítica não empurra para cima os óbitos relacionados a essa carência desse serviço socioambiental.

As doenças infecciosas e suas características segundo o Ministério da Saúde (2010) são predominantemente de veiculação hídrica e estão associadas com condições inadequadas de saneamento básico, deficiência de higiene pessoal/ambiental. A deficiência do abastecimento de água tratada, destino inadequado dos dejetos, alta densidade populacional, carências de habitação, higiene inadequada, alimentação precária são elencados fatores potenciais que podem comprometer a saúde humana (BRASIL, 2010). Condições que são evidenciadas no ambiente urbano dos Distritos de Vila do Conde e Murucupi. Portanto as populações desse recorte intraurbano estão sujeitas a ocorrência dessas patologias socioambientais.

O sistema de esgotamento sanitário de Barcarena é composto por apenas 01 (um) sistema, localizado na Vila dos Cabanos onde atualmente existe apenas a coleta, afastamento e lançamento dos efluentes, estando em fase de implantação uma estação de tratamento de esgoto (ETE). Nos demais bairros que fazem parte dos Distritos do Murucupi e Vila do Conde constatou-se que não há sistema de afastamento do esgoto sanitário, sendo adotado como procedimento "padrão" para impedir formas de infestações infecciosas à construção de fossas subterrâneas com medidas de $1 \mathrm{~m} \times 1 \mathrm{~m}$ de largura ou $1 \mathrm{~m} \mathrm{x}$ $2 \mathrm{~m}$ de largura e comprimento, por $2,0 \mathrm{~m}$ de profundidade, sendo as laterais de alvenaria e fundo consideradas sumidouro. Cada residência dispõe de pelo menos duas fossas: uma sanitária e a outra para rejeitos de gordura.

O IBGE (2020) estima que 27,8\% de domicílios dispõe de esgotamento sanitário adequado em Barcarena. Barcarena (2013) estimou o índice de coleta de esgotos em 25\%. Com base nos dados levantados estimou-se nesta pesquisa o percentual de $26 \%$ de domicílios integrados a rede de esgotamento sanitário. A Tabela 2 apresenta o les com base nos dados.

Tabela 2: Produto parcial do Índice de Esgotamento Sanitário dos Distritos de Murucupi e Vila do Conde, Barcarena.

\begin{tabular}{|l|c|c|c|}
\hline Tipo de Esgotamento & $\begin{array}{c}\text { Quantificação das formas de } \\
\text { disposição do esgoto } \\
\text { (\%) }\end{array}$ & $\begin{array}{c}\text { Produto das formas de } \\
\text { disposição do esgoto }\end{array}$ & $\begin{array}{c}\text { Indicador do Esgotamento } \\
\text { Sanitário (les) }\end{array}$ \\
\hline Rede de esgoto com tratamento & 0 & 0 & 0,14 \\
\hline Rede de esgoto ou águas pluviais & 26 & 0,028 & 0,13 \\
\hline $\begin{array}{l}\text { Fossa séptica com sumidouro ou } \\
\text { afastamento }\end{array}$ & 7,0 & 0,122 \\
\hline Fossa rudimentar & 61,0 & 0,004 & 0 \\
\hline Vala ou escoadouro & 4,0 & 0 & \\
\hline Sem dispositivo de afastamento & 2,0 & 0 & \\
\hline
\end{tabular}

O les apresentou pontuação ínfima, 0,13 ponto, revelando um grave problema socioambiental em Barcarena, visto que o sistema de esgotamento sanitário está relacionado com a qualidade e a expectativa de vida da população, com a proteção do meio ambiente e com o desenvolvimento urbano. E a deficiência e mesmo a ausência desse sistema de coleta de esgoto sanitário e seu tratamento em Barcarena, expõem os meios natural e construído e a própria sociedade aos efeitos danosos dos efluentes lançados no sistema de drenagem, no solo, nos corpos d'água, contribuindo para o aumento da degradação dos mananciais de água e, consequentemente impactando direta e indiretamente na saúde da população de Barcarena. 
Portanto o problema de saneamento básico em Barcarena demonstra-se grave, pois a maior parte dos domicílios não tem acesso ao sistema geral de esgotamento, que na prática é quase inexistente, havendo a instalação de alternativas sanitárias para despejo dos efluentes domésticos; valendo-se de fossas rudimentares, valas, rios ou outro mecanismo ejetor de rejeitos domésticos. Posto não haver sistema de esgoto pluvial ou forma de afastamento pluvial dos domicílios na área de aglomeração subnormal e comunidades quilombolas nos bairros do Distrito Industrial de Barcarena, apenas a Vila dos Cabanos apresenta esgotamento sanitário não havendo forma de tratamento para o esgoto. $O$ sistema de tratamento de esgoto para Vila dos Cabanos está em fase implantação.

A Figura 2 ilustra as condições de saneamento da área de estudo através da espacialização da cobertura do sistema de esgotamento sanitário na área do entorno industrial de Barcarena possibilitando a visualização das condições sanitárias precárias que enfrenta a população barcarenense, evidenciando a vulnerabilidade às doenças que podem incidir nesta área urbana amazônica.

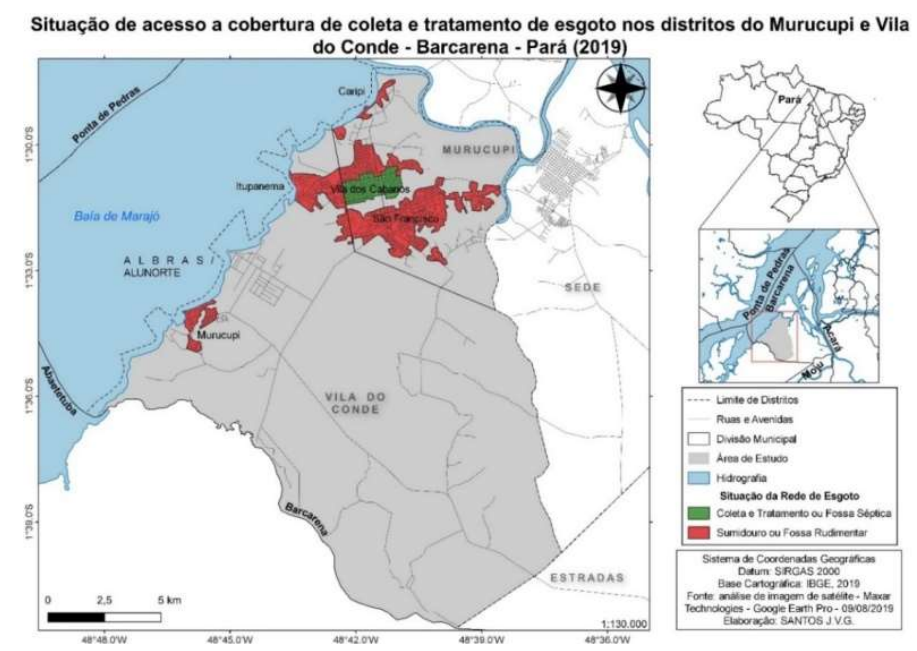

Figura 2: Situação de acesso à cobertura de coleta e tratamento de esgoto nos Distritos do Murucupi e Vila do Conde, Barcarena, Pará, 2019.

Em 2017 dos 468 óbitos (IBGE, 2020) em Barcarena apenas 22 podem ser presumíveis as questões conexas às condições de saneamento básico, entre elas o sistema de esgoto sanitário. $\mathrm{O}$ que em percentuais corresponde a níveis de obituário baixos. No entanto a fragilidade do sistema de esgoto sanitário traça um prognóstico preocupante para os próximos anos, pois o acúmulo de efluentes domésticos em ambiente aberto, natural ou construído, impõe riscos à saúde da população e aos ecossistemas naturais.

A Organização Mundial de Saúde (OMS, 2016) lista os principais riscos à saúde humana associada à precariedade no sistema de esgotamento saneamento, sendo um indicador importante para a avaliação de patógenos em resíduos contaminados com matéria fecal, bem como para a eficiência das medidas de controle do tratamento, é a não manifestação de Escherichia coli. Outro dado relevante é a ocorrência de tremátodes e esquistossomose, uma vez que a transmissão desses agentes de doenças pode ser através de peixes, plantas aquáticas ou exposição à água contaminada. Os ambientes de rejeitos de drenagem superficial (valas) ou outros locais inadequados de acúmulos de efluentes domésticos podem servir de 
Estudo da qualidade socioambiental urbana dos distritos do Murucupi e Vila do Conde em Barcarena Pará com uso de indicadores ambientais urbanos

MELO, F. A.; PIMENTEL, M. A. S.; LEITE, T. V. S.

locais para a reprodução de insetos vetores o que aumenta o risco de transmissão de doenças por esses vetores (OMS, 2016).

A limpeza pública no Bairro Industrial é considerada eficiente, definindo-se por parte da empresa coletora três dias na semana para a coleta de resíduos sólidos em cada área. Em todas as comunidades visitadas os informantes afirmaram que estão satisfeitos com a coleta de resíduo sólido no bairro. Não foram constatados acúmulos de resíduo sólido nas ruas. E em relação aos entulhos a prefeitura disponibiliza a coleta uma vez por mês. E nas comunidades quilombolas indígenas em meio urbano detectaram-se duas formas de coleta: a) coleta três vezes na semana (similar aos bairros da área urbana) e, b) uma vez na semana os moradores colocam em locais estratégicos para que o carro coletor recolha o lixo.

Do lixo coletado $91 \%$ do lixo é por serviço de limpeza, $7 \%$ coletado por caçamba de serviço de limpeza e $2 \%$ queimado na propriedade (INFOSANBAS/IBGE, 2020). Para assegurar a veracidade da informação foram realizadas visitas periódicas de campo com base na observação participante e no método aleatório simples que considera como verdade a constatação contínua do mesmo fato em uma determinada área de sua incidência. Obteve-se o produto Ilpu 0,98 ponto.

O Bairro Industrial que engloba os distritos do Murucupi e Vila do Conde não dispõe de aterro sanitário como determina a Lei no 12.305/2010; o depósito de lixo (lixão) localiza-se no bairro Bom Futuro, a céu aberto sem qualquer controle sanitário, havendo a utilização de maquinário para revolver e "organizar" em montanhas de resíduos o material que chega aos caminhões coletores. Há um grande número de pessoas que se aglomeram junto aos caminhões para retirarem o material que pode ser aproveitado para a reciclagem, o que expõe esses grupos de indivíduos aos riscos à sua saúde.

Nos lixões os resíduos são depositados sobre o terreno, sem nenhum preparo do mesmo, e também sem nenhum tratamento dos efluentes líquidos derivados da decomposição do lixo, como o chorume, que percola o solo, contaminando o lençol freático. Ainda mais, os lixões deixam um aspecto social negativo, visto que são fonte de renda e alimento para uma parcela da população abaixo da linha da pobreza que busca nele alimento e materiais recicláveis. Essa população é a que está mais sujeita aos efeitos nocivos dos vetores de doenças e das substâncias tóxicas presentes no lixão (BRASIL, 2011).

As vias urbanas são classificadas como ruas, avenidas, vielas, ou caminhos e similares aberto à circulação pública, caracterizados principalmente por possuírem imóveis edificados ao longo de sua extensão, por isso são à base da circulação e da mobilidade da vida urbana. E assim deveriam dispor de condições adequadas de infraestrutura, entre elas a pavimentação.

Em Barcarena a situação das rodovias estaduais, PA 481 e PA 483, que dão acesso ao município e o núcleo da Vila dos Cabanos apresentam pavimentação asfáltica contínua. Contudo, a falta de manutenção e o fluxo intenso de caminhões por esses trechos, que atendem ao complexo industrial e ao Porto de Vila do Conde, deixaram essas vias em condições precárias, com buracos e faixas sem asfalto, além de outros estragos na sua feição paisagística.

Nos aglomerados subnormais que estão no entorno dos grandes empreendimentos, localizados nos Distritos do Murucupi e Vila do Conde, não há uma pavimentação contínua, apenas as ruas principais de 
Estudo da qualidade socioambiental urbana dos distritos do Murucupi e Vila do Conde em Barcarena Pará com uso de indicadores ambientais urbanos

MELO, F. A.; PIMENTEL, M. A. S.; LEITE, T. V. S.

cada bairro apresentam pavimentação, porém descontínua. As demais vias complementares não apresentam pavimentação. A Tabela 3 detalha a extensão das vias pavimentadas e não pavimentadas.

Tabela 3:Extensão das vias pavimentadas e não pavimentadas

\begin{tabular}{c|c}
\hline Vias & Extensão em $\mathbf{k m}$ \\
\hline Pavimentadas & 224,9 \\
\hline Não Pavimentadas & 222,7 \\
\hline Total & 447,6 \\
\hline
\end{tabular}

Os dados apresentados na Tabela 3 indicam que 50,25\% das vias de tráfego são pavimentas e por conseguinte $49,75 \%$ são vias não pavimentadas. Não sendo considerada a qualidade da pavimentação asfáltica. O IBGE (2020) aponta que 16,2\% dos domicílios urbanos em Barcarena dispõem de vias com urbanização adequada (presença de bueiro, calçada, pavimentação e meio-fio). Obteve-se o Ipav 0,50 ponto. Considerando os aspectos físicos das vias não asfaltadas e a inexistência de galerias de esgotos pluviais, associados à dinâmica climática da região Amazônica que tem um longo período chuvoso, faz-se a seguinte dedução lógica: a não pavimentação asfáltica sob certas circunstâncias impede eventos mais calamitosos como alagamentos; o que com a pavimentação traria mais transtornos para a população, pois, o solo das vias se tornaria impermeável. A Figura 3 ilustra a disposição das vias pavimentadas e não pavimentadas do entorno industrial da área de estudo tecendo quadro intermediário desse indicador para a qualidade ambiental urbana.

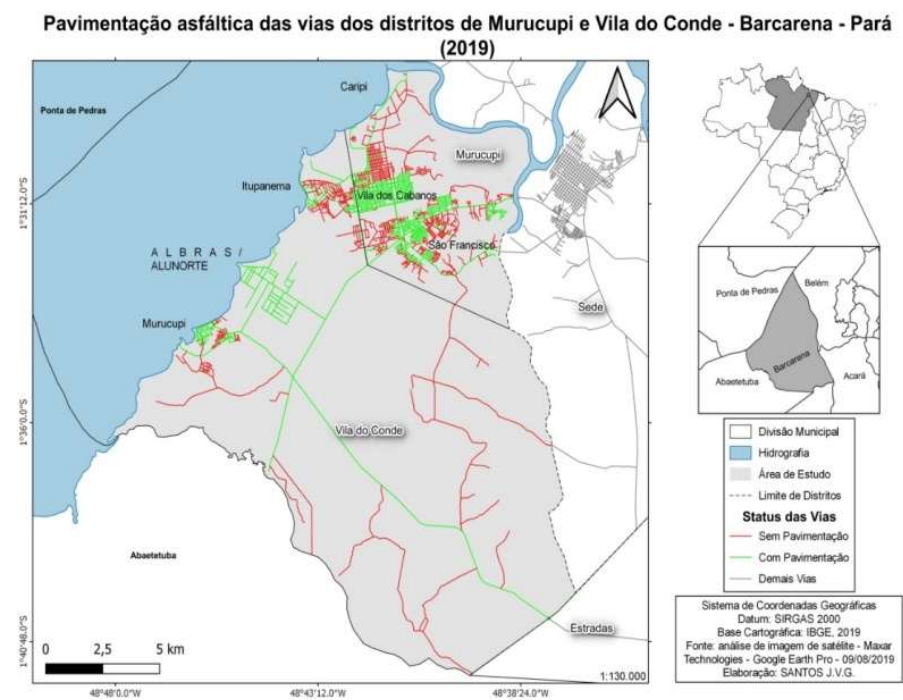

Figura 3: Pavimentação asfáltica das vias dos distritos do Murucupi e Vila do Conde, Barcarena, PA.

As artérias viárias de Barcarena conforme assinala a Figura 3 não cumprem eficientemente a função a qual são destinadas que é assegurar a circulação de pessoas, veículos, valores e mercadorias, isto é, manter a vida urbana em organicamente movimento. Especialmente porque nos períodos mais chuvosos (Dezembro a Abril) essas vias não pavimentadas estão mais sujeitas aos efeitos das intempéries provocadas pela precipitação como infere a Tabela 4.

A Tabela 4 apresenta a precipitação acumulada entre os anos 2015 a 2019 na cidade de Barcarena, sendo que esta amostragem tem como finalidade explicar a relação ambiental entre os impactos negativos 
Estudo da qualidade socioambiental urbana dos distritos do Murucupi e Vila do Conde em Barcarena Pará com uso de indicadores ambientais urbanos

MELO, F. A.; PIMENTEL, M. A. S.; LEITE, T. V. S.

da precipitação no sistema viário dos Distrito do Murucupi e Vila dos Cabanos, especificamente nos períodos mais chuvosos, Dezembro a Maio, como descreve a Tabela 5. Visto que entre os múltiplos danos socioambientais provocados pela precipitação intensa na Amazônia, em específico nesta faixa urbana, pela ausência de pavimentação asfáltica, tem-se a ocorrência de lamaçais e crateras ao longo das vias, revelando uma paisagem urbana degradada e pouco eficiente em atender as necessidades de mobilidade urbana, além de provocar transtornos cotidianos aos moradores destes núcleos distritais de Barcarena.

Tabela 4: Precipitação acumulada mensal registrada entre os anos de 2015 a 2019 na cidade de Barcarena-PA

\begin{tabular}{|c|c|c|c|c|c|c|c|c|c|c|c|c|c|}
\hline & & \multicolumn{12}{|c|}{ Meses } \\
\hline Ano & \multirow{6}{*}{ 递 } & Jan & Fev & Mar & $A b r$ & Mai & Jun & Jul & Ago & Set & Out & Nov & Dez \\
\hline 2015 & & 315,9 & 243,7 & 394,2 & 413,8 & 298,2 & 159,4 & 150,8 & 85,2 & 75,5 & 37,8 & 39,0 & 95,5 \\
\hline 2016 & & 281,7 & 342,3 & 413,7 & 301,5 & 266,5 & 104,3 & 146,0 & 102,2 & 90,9 & 80,4 & 55,0 & 308,8 \\
\hline 2017 & & 544,8 & 399,1 & 447,8 & 387,2 & 257,6 & 157,7 & 78,6 & 149,1 & 89,3 & 148,0 & 30,5 & 225,0 \\
\hline 2018 & & 275,7 & 406,7 & 408,1 & 350,5 & 386,6 & 104,1 & 127,8 & 186,5 & 129,7 & 76,7 & 194,6 & 406,8 \\
\hline 2019 & & 352,0 & 396,4 & 461,5 & 453,2 & 391,6 & 213,2 & 159,7 & 160,5 & 184,2 & 205,5 & 126,4 & 326,2 \\
\hline
\end{tabular}

Tabela 5: Impactos socioambientais da precipitação sobre as vias não pavimentadas dos Distritos do Murucupi e Vila do Conde, Barcarena-Pará.

\begin{tabular}{|c|c|c|c|}
\hline Ano & Meses & Precipitação (mm) & Riscos e Impactos socioambientais* \\
\hline 2015 & \multirow{7}{*}{ Dezembro a Maio } & 1761,3 & Formação de buracos ou crateras \\
\hline 2016 & & 1914,6 & Lamaçal ao longo das vias \\
\hline 2017 & & 2261,5 & Redução da velocidade dos veículos \\
\hline \multirow{2}{*}{2018} & & \multirow{2}{*}{$2.234,4$} & Danos ao meio de transporte \\
\hline & & & Estresse na população \\
\hline \multirow{2}{*}{2019} & & \multirow{2}{*}{$2.380,9$} & Riscos de acidentes de trânsito \\
\hline & & & Degradação da paisagem urbana \\
\hline
\end{tabular}

* Esses riscos e impactos socioambientais se manifestam de maneira cíclica e simultaneamente ao longo do período indicado $(2015-2019)$.

A condição ambiental adequada das vias de acesso permite circular pessoas, bens e serviços urbanos de modo a manter e desenvolver a cidade, constituindo-se em um fator fundamental para a vida na urbe. Contudo as condições inadequadas do Ipav 0,50 ponto, dos Distritutos do Murucupi e Vila do Conde impõem restrições físicas e riscos socioambientais diversos que potencialmente ameaçam ao bem estar, a saúde e a qualidade da população conforme aponta a Tabela 9, que limitam o seu uso e agravam as desigualdades socioambientais neste meio intranurbano, estabelecendo uma mobilidade urbana deficitária que impede o direito à cidade socioambientalmente desenvolvida.

A Figura 4 destaca as principais áreas de riscos de acidentes outros eventos sinistros nos Distritos do Murucupi e Vila do Conde enquanto reflexo da má qualidade das vias de tráfego em Barcarena, e que potencial e realmente somam para o decréscimo significativo da qualidade ambiental urbana de Barcarena, e por conseguinte, se consolidam em tecer um espaço urbano segregador dos direitos socioambientais dos seus cidadãos.

A Tabela 6 expressa a classe e as áreas do uso do solo dos Distritos do Murucupi e Vila do Conde, Barcarena, no ano de 2020 possibilitando a quantificação da cobertura vegetal para se extrair o Icv da área de estudo. 


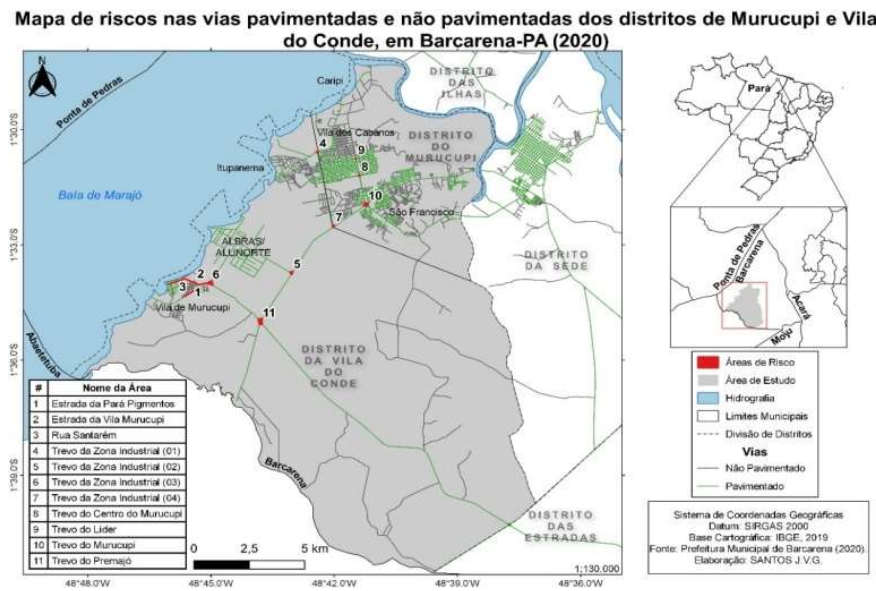

Figura 4: Mapa de riscos nas vias pavimentadas e não pavimentadas dos Distritos do Murucupi e Vila do Conde - Barcarena-PA (2020).

Tabela 6: As áreas das classes de uso do solo dos Distritos do Murucupi e Vila do Conde, Barcarena, PA - 2020.

\begin{tabular}{l|c}
\hline \multicolumn{1}{c}{ CLASSES } & Área $(\mathbf{k m 2}$ \\
\hline Vegetação densa & 201,8 \\
\hline Vegetação secundária & 244,2 \\
\hline Vegetação rasteira & 124,9 \\
\hline Mineração & 2,6 \\
\hline Área estruturada & 59,9 \\
\hline Massas d'águas & 327,9 \\
\hline Nuvens & 2,9 \\
\hline Sombra de nuvens & 0,8 \\
\hline Área total & 965 \\
\hline
\end{tabular}

O produto do Icv 0,46 ponto o que aponta um indicador de cobertura vegetal ainda tolerável, e corresponde à amenização do microclima desta faixa territorial urbana, além de se ter à ornamentação urbana, a defesa e a recuperação do meio ambiente em face da degradação de agentes poluidores. Especificamente porque esta unidade espacial intraurbana localiza-se na zona equatorial, que faz parte do clima quente equatorial úmido na classificação de Köppen, do tipo Am, e a temperatura média anual é de $27^{\circ} \mathrm{C}$, o que indica gradientes de temperaturas elevadas o ano todo.

A análise da Tabela 6 retrata uma cobertura vegetal (floresta densa e floresta secundária) com 446 $\mathrm{km}^{2}$ em 2020, o que corresponde $46,21 \%$ de área verde, evidenciando-se ainda uma significativa cobertura arbórea, nos Distritos do Murucupi e Vila do Conde, o que permite nesse meio urbano, mesmo estando localizado na zona equatorial, dispor sob certas condições intraurbanas de gradientes de equilíbrio térmico, volatilização das massas de ar, amenização da sensação térmica de calor extremo, filtração dos gradientes de dióxido de carbono melhorando a qualidade do ar, o que em particular esta variável ambiental possibilita uma melhor qualidade de vida da população residente nesses distritos de Barcarena.

A cobertura vegetal é a chave da interação de equilíbrio superfície terrestre-atmosfera especialmente no ambiente urbano, visto possuir infinitas funções no espaço urbano e seus arredores não urbanos, pois é responsável pela amenização do microclima das cidades, servindo de delimitador de espaços, absorvendo os ruídos, purificando o ar com a absorção das partículas tóxicas e de poeiras, diminuindo o albedo dos objetos, ou seja, a reflectância da energia solar, promovendo um ambiente adequado à moradia e ao bem estar da população urbana (BORGES et al, 2010). 
A Figura 5 expressa um avanço da mancha de ocupação antrópica e a redução gradativa da cobertura verde densa, que está em alguns casos em áreas públicas municipais; territórios quilombolas indígenas; áreas privadas e coberturas verdes secundárias (capoeira dispersa, quintais domiciliares e arborização das ruas). A mancha arbórea não compõe os corredores viárias que são incipientes de arborização, que apresenta 7,8\% do espaço intraurbano dos Distritos do Murucupi e Vila do Conde (IBGE, 2020).

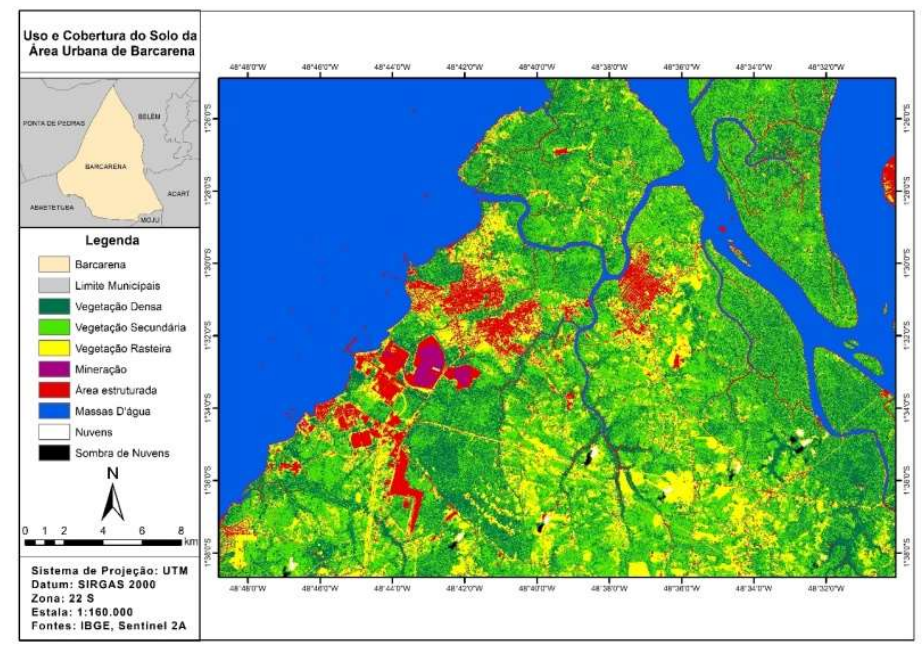

Figura 5: Mapa de análise do uso e ocupação do solo dos Distritos de Vila do Conde e Murucupi - PA (2020).

A Figura 5 permite argumentar que em Barcarena ainda existe uma reserva significativa de cobertura vegetal, que corresponde à área de floresta primária e secundária. E este fator ecológico mantém e sustenta a vida dos habitantes urbe e a outros ecossistemas vizinhos dessa faixa urbana amazônica, uma vez que as baixas latitudes equatoriais recebem uma grande quantidade de insolação o ano todo. Caso ocorra a diminuição da cobertura vegetal o processo de evapotranspiração diminui consideravelmente, elevando a temperatura da cidade (NOBREGA, 2014).

A Figura 6 apresenta uma série temporal das temperaturas mínimas e máximas em Barcarena no período de 2015 a 2019. Referenciamos média máxima anual em 2015 foi 30,9 ㄷ, em 2016 foi 31,2 ำ, em 2017 foi 30,9 @C; em 2018 30,6C, e em 2019 30,6 @C. identificamos que as temperaturas atingidas ao longo do período selecionado demonstram que a população de Barcarena enfrenta um estresse térmico contínuo que impacta na sua qualidade de vida, pois temperaturas elevadas provocam inúmeras sensações no indivíduo como cansaço moderado e cansaço extremo, perda de líquido, queimaduras cutâneas, sensação de desconforto térmico, estresse térmico (FEITOSA, 2019).

Entre as doenças suscetíveis ao clima constam as cardiovasculares, respiratórias agudas e crônicas, diarreicas agudas, mentais, transmitidas por vetores, má nutrição, lesões na pele (OPAS, 2014). Por isso ao se analisar a Figura 6, conclui-se que a população devido às temperaturas elevadas associadas à fragilidade dos corredores verdes urbanos (arborização) fica à mercê de possíveis adoecimentos causados pelas condições restritivas socioambientais de uma cobertura arbórea nas vias públicas no percentual de 7,8\%, que expõe os pedestres as condições de insolação direta, não havendo abrigos arbóreos para amenizar os rigores da radiação solar, impondo uma sensação térmica de calor moderado a extremo neste recorte 
urbano, especificamente em períodos de calor mais intensos.

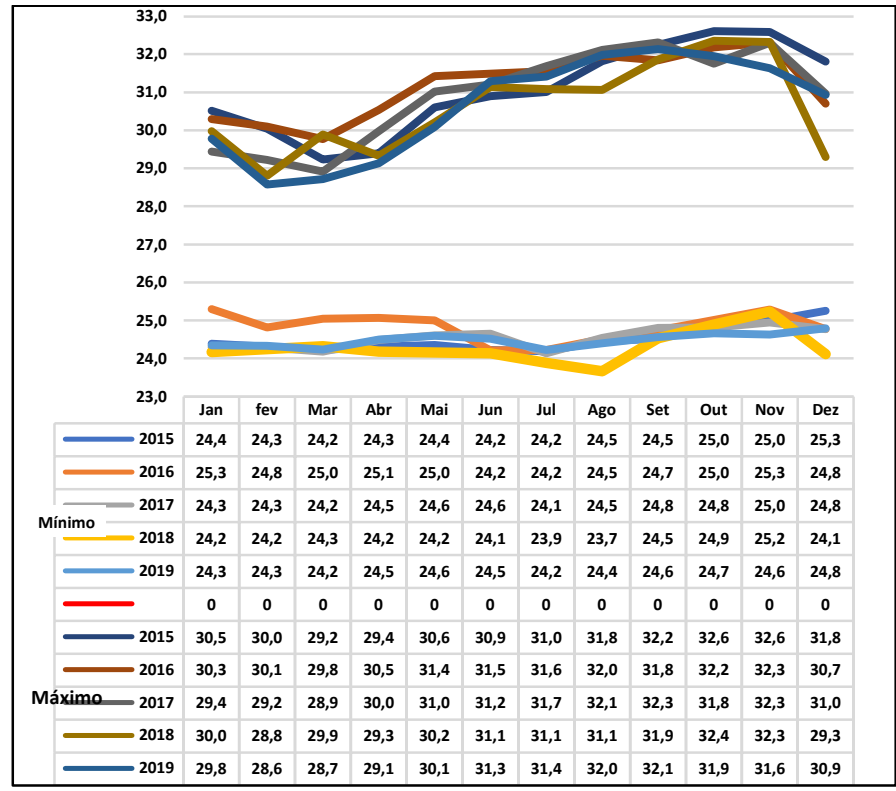

Figura 6: Variabilidade mensal média Médias de temperaturas mensais (2015 - 2019)

Frisa-se ainda que ainda não exista um plano municipal de arborização para Barcarena, e nas áreas e nos corredores urbanos (ruas, passagens, praças, áreas livres) visitados a arborização detectada mostrouse de forma incipiente, sendo promovida pelos moradores dos Bairros. Apenas a Vila dos Cabanos (Distrito do Murucupi) apresenta uma arborização planejada fruto da herança do período áureo em que estava na condição de Company Town do Projeto Albrás-Alunorte (1980-1990).

Realizada a consolidação e descrição do produto de cada indicador, faz-se a discussão do Índice da qualidade ambiental dos Distritos do Murucupi e Vila do Conde (áreas do entorno urbano dos Grandes Empreendimentos em Barcarena). A Tabela 7 organiza os índices parciais que definem quantitativamente o índice de qualidade ambiental urbana deste entorno urbano-industrial.

Tabela 7: Indicadores parciais e o Índice de qualidade ambiental dos Distritos do Murucupi e Vila do Conde Barcarena-PA.

\begin{tabular}{|c|c|c|c|c|c|}
\hline & & de Qualidad & ental Urbana & & \\
\hline Indicadores & $\begin{array}{l}\text { Índices } \\
\text { parciais }\end{array}$ & $\begin{array}{l}\text { Peso dos } \\
\text { Indicadores }\end{array}$ & Produtos Parciais & Produto Final & Nível do IQAU \\
\hline labs & 0,24 & 15 & 3,6 & \multirow{5}{*}{44,8} & \multirow{5}{*}{ Ruim } \\
\hline les & 0,13 & 35 & 4,8 & & \\
\hline IIpu & 0,98 & 20 & 19,6 & & \\
\hline Ipav & 0,50 & 15 & 7,5 & & \\
\hline ICV & 0,62 & 15 & 9,3 & & \\
\hline
\end{tabular}

O índice de qualidade ambiental dos Distritos do Murucupi e Vila do Conde evidencia um cenário socioambiental adverso, pois o nível da qualidade ambiental a partir da agregação dos indicadores mostrase ruim (44,8 pontos). E isso é o reflexo das condições socioambientais insalubres das áreas intraurbanas e precária qualidade dos seus equipamentos urbanos, com riscos à qualidade de vida, e por conseguinte, a sua saúde das populações residentes nos recortes territoriais desta cidade amazônica.

O labs 3,6 pontos reflete falha grave na gestão pública, demonstrando as limitações administrativas 
Estudo da qualidade socioambiental urbana dos distritos do Murucupi e Vila do Conde em Barcarena Pará com uso de indicadores ambientais urbanos

MELO, F. A.; PIMENTEL, M. A. S.; LEITE, T. V. S.

das esferas públicas que se refletem em uma sociedade que fica a margem das condições de saneamento básico ideais. Revelando um quadro de segregação e marginalização da população que reside no entorno dos grandes empreendimentos em Barcarena. E isto fere o seu direito ao acesso aos serviços de saneamento básico enquanto condição indispensável à dignidade da pessoa humana e, particularmente, à sua sobrevivência. E ao se limitar este acesso a níveis abaixo de $50 \%$ dos domicílios, traça-se uma perspectiva a médio e longo prazos tendencia a puxar para baixo a curva da qualidade de vida dessas populações, pois as populações sem água encanada estão sujeitas a um tipo de água que não passou por nenhuma forma de verificação de sua potabilidade, colocando-as sob frequentes riscos de ingestão de água contaminada.

O produto do les mostra-se muito baixo, 4,8 pontos, estimando-se que a população está sujeita ao comprometimento da sua saúde, como doenças de veiculação epidemiológica; o que representa ameaça direta a qualidade e expectativa de vida, e a proteção do meio ambiente e ao desenvolvimento urbano de Barcarena. A ausência ou ineficiência do esgotamento sanitário é um dos fatores de degradação da qualidade da água e da poluição resultante do lançamento dos esgotos sanitários coletados em corpos d'água, havendo a necessidade da destinação e do tratamento desses efluentes na sua maioria domésticos, de modo a minimizar a carga poluidora antes de sua disposição final, o que não ocorre nessa faixa urbana, posto o sistema de esgotamento sanitário mostrar-se incipiente.

O Ilpu mostrou excelente desempenho, pois atingiu pontuação próxima ao nível máximo, 19,6 pontos. A condição satisfatória desse indicador elevou o IQAU, e na prática inibe a possibilidade de proliferação insetos, animais e microrganismos veiculadores de doenças, posto que a ausência e ou deficiência na coleta de lixo, associada ao manuseio e à disposição inadequados dos resíduos sólidos, é importante fator de risco para a saúde humana.

O Ipav totalizou 7,5 pontos e seus impactos comprometem a circulação de pessoas e mercadorias, essenciais à manutenção da vida urbana. Bem como podem comprometer a instalação de calçadas, arborização e a instalação de outros equipamentos urbanos. Sem um corredor viário adequado o desenvolvimento socioambiental urbano dos Distritos do Murucupi e Vila do Conde fica comprometido.

O ICV pontuou 9,3 pontos correspondendo a uma condição socioambiental neste quesito ainda é satisfatória, estando consagrado que as áreas verdes urbanas executam reconhecidos serviços ecológicos: protegem os recursos hídricos, mitigam os impactos de eventos climáticos extremos, a redução de uma série de doenças (cardíacas, pulmonares, psicológicas e relacionadas à poluição e degradação ambiental), estabilização de superfícies por meio da fixação do solo pelas raízes das plantas; obstáculos contravento; equilíbrio de umidade e temperatura; proteção de nascentes, de mananciais e da qualidade da água; abrigo de fauna; valorização visual e ornamental do ambiente; segurança das calçadas como acompanhamento viário; recreação; consumo de vegetais e frutas frescas, não havendo limites para os seus benefícios nos espaços intraurbanos (MMA, 2020). Portanto a cobertura vegetal nas cidades desempenha papel-chave no equilíbrio ambiental urbano e sua manutenção corresponde às diretrizes de políticas públicas que objetivam o desenvolvimento sustentável das cidades. 
O IQAU com valor 44,8 pontos expressa condições socioambientais dos Distritos do Murucupi e Vila do Conde que evidenciam um nível ruim, ou seja, a extensão espacial urbana de Barcarena compromete a saúde, a qualidade de vida e marginaliza, principalmente, socioambientalmente as minorias sociais urbanas que estão sujeitas aos mais variados riscos socioambientais: a) doenças infecciosas de veiculação hídrica; b) riscos à saúde humana provocada pela ausência de esgoto sanitário; c) riscos à saúde provocados pelo acúmulo inadequado de resíduos sólidos de componentes industriais potencialmente perigosos; d) impactos socioambientais da precipitação sobre as vias não pavimentadas; e) eventos extremos climáticos na área urbana. Corrobora com esta análise a Organização Pan-Americana da Saúde (OPAS, 2014) esclarecendo que a vulnerabilidade de ambientes, especificamente urbanos, gera toda sorte de problemas socioambientais: estresse térmico, eventos meteorológicos extremos, contaminação do ar, doenças infecciosas transmitidas pela água, pelos alimentos e por vetores, desnutrição, doenças infecciosas transmitidas por vetores, exposição à luz ultravioleta (radiação ultravioleta).

Nesta linha na Tabela 8 são elencados morbidades e óbitos com causais prováveis relacionadas às condições da fragilidade da qualidade ambiental urbana de Barcarena. Visto que o IQAU com nível ruim expresso nos seus territórios intraurbanos impõe níveis perigosos de vulnerabilidade à saúde da população. Assim, pode-se presumir com razoabilidade que certas morbidades e óbitos ocorridos em Barcarena podem estar associados aos eventos de ordem socioambiental adversa, sendo eles os distúrbios climáticos, a precariedade no saneamento, a inadequação na disposição dos resíduos sólidos em ambientes impróprios, dentre outros, que são causadores das doenças infecciosas e parasitárias, as doenças do aparelho respiratório, as doenças do aparelho digestivo, as doenças da pele e do tecido subcutâneo e as causas externas de morbidade e mortalidade.

Tabela 8: Número de óbitos que podem ser associados às causas socioambientais e as condições climáticas, por sexo ano 2017.

\begin{tabular}{|c|c|c|c|}
\hline \multirow{2}{*}{ Morbidade } & \multicolumn{2}{|c|}{ № de Óbitos por Sexo } & \multirow{2}{*}{ Total de Óbitos } \\
\hline & $\mathbf{M}$ & $\mathbf{F}$ & \\
\hline Algumas doenças infecciosas e parasitárias & 16 & 6 & 22 \\
\hline Doenças do aparelho circulatório & 50 & 46 & 96 \\
\hline Doenças do aparelho respiratório & 26 & 30 & 56 \\
\hline Doenças do aparelho digestivo & 19 & 8 & 27 \\
\hline Doenças da pele e do tecido subcutâneo & - & 1 & 1 \\
\hline
\end{tabular}

Fonte: IBGE (2020).

Portanto a qualidade ambiental urbana dos Distritos do Murucupi e Vila do Conde expressa pelos indicadores de limpeza pública, esgotamento sanitário, abastecimento de água, pavimentação das vias e cobertura vegetal configuram um ambiente intraurbano socioambientalmente deficitário e precário que compromete a qualidade de vida e a saúde da população de Barcarena, em particular as populações vulneráveis socioeconomicamente, pois residem em locais que apresentam riscos às condições sanitárias, ausência de acesso à água potável, baixas ou inexistentes corredores e faixas arborizadas, vias de tráfego sem pavimentação e deterioradas pela precipitação extrema, destinação inadequada de lixo e dejetos.

A expressão da qualidade ambiental dos Distritos de Murucupi e Vila do Conde em Barcarena 
Estudo da qualidade socioambiental urbana dos distritos do Murucupi e Vila do Conde em Barcarena Pará com uso de indicadores ambientais urbanos

MELO, F. A.; PIMENTEL, M. A. S.; LEITE, T. V. S.

através da cor em laranja tem significado qualitativo de demonstrar que o valor atingido do IQAU 44,8 pontos está próximo ao nível vermelho, o que reflete a realidade intraurbana de instabilidade e vulnerabilidade socioambiental, estabelecendo uma ordem socioambiental urbana fragilizada pela insuficiência e precariedade dos equipamentos urbanos de saneamento, fornecimento de água potável, arborização, coleta de resíduos sólidos e sua destinação tecnicamente adequadas, vias devidamente pavimentadas e sinalizadas. E esta ordem socioambiental constitui-se em risco a qualidade de vida e a saúde da população habitante dos Distritos do Murucupi e Vila do Conde em Barcarena.

E mais, esta unidade intraurbana por estar localizada na borda da planta industrial minerometalúrgica e a sua malha produtiva agressiva está sujeita a inúmeros desastres ambientais que impõem impactos e contaminações das mais variadas extensões e repercussões socioambientais, que causam danos irreparáveis ao meio construído de Barcarena, as suas populações e aos ecossistemas naturais circunvizinhos com sua biodiversidade.

Pois ao longo dos últimos vinte e cinco a população de Barcarena, em específico as populações residentes dos Distritos do Murucupi e Vila do Conde, têm enfrentado sucessivos desastres ambientais, listados a seguir: a) Naufrágio da balsa Miss Rondônia no Porto de Vila do Conde, houve o derramamento de aproximadamente dois milhões de litros de óleo BPF no rio Pará (2000) ; b) Derramamento, no rio Pará, Porto de Vila do Conde, de cerca de $100 \mathrm{Kg}$ (cem quilos) de coque (pó preto derivado do petróleo, também conhecido como carvão mineral) (2002); c) Vazamento de grande proporção de lama vermelha de bacias de rejeitos da ALUNORTE no Rio Murucupi (2003); d) Chuva de fuligem em praias, rios, residências e estabelecimentos comerciais foram cobertos de material particulado com coloração preta, não tendo havido definição sobre a identificação da empresa responsável pela ocorrência, sendo que a fuligem, que chegou a atingir $5 \mathrm{~cm}$ de espessura, gerou reação alérgica e complicações respiratórias em grande quantidade de pessoas em Vila do Conde (2003); e) Novo vazamento de material proveniente de bacias de rejeito na IMERYS e Contaminação dos cursos d'água (2006); f) Novo acidente ambiental envolvendo rejeito da empresa IMERYS de proporção ainda maior, atingindo o rio Pará; g) Vazamento de óleo das instalações da PETROBRÁS na Vila do Conde (2008); h) Naufrágio do rebocador Jeany Glalon XXXII no Furo do Arrozal, com vazamento de aproximadamente 30.000 (trinta mil) litros de óleo e uma mancha de aproximadamente17 Km de extensão (2008); i) Mais um episódio de vazamento de lama vermelha das bacias de rejeito da Alunorte no Distrito Industrial de Barcarena, talvez o acidente ambiental mais grave da história do Distrito Industrial de Barcarena, atingiu várias pessoas e comunidades do Município (2009); j) Nuvem de fuligem Encobriu todo o Bairro Industrial do Município de Barcarena (2010); K) Rompimento de duto com efluentes ácidos da IMERYS nos Igarapés Curuperê e Dendê (2011). Vazamento de material das bacias de rejeito da Imerys (2012). Vazamento de rejeito da IMERYS e levou a Ação cautelar ajuizada pelo MPF e MPPA na Justiça Federal de Belém - Assinatura de TAC (2014); k) Naufrágio de embarcação com centenas de bois vivos com graves impactos ambientais sobre toda a região, sendo a questão objeto de ação civil pública em andamento na Justiça Federal de Belém (2015) (MPEPA; MPF, 2016).

Esses desastres ambientais produziram uma cena caótica socioambiental urbana depreciando ainda 
mais a qualidade ambiental urbana dos Distritos do Murucupi e Vila do Conde, que apresenta nível ruim, posto acrescentar riscos mais graves a qualidade de vida e a saúde dos habitantes dessas unidades territoriais intraurbanas, pois estão sujeitos a contaminações que podem causar comorbidades e em si óbitos iminentes. E mais dramático ainda, esses desastres deixam os ambientes urbano e natural de Barcarena com risco permanente, pois os rejeitos contaminantes continuam ativos por longo período e ameaçam a qualidade de vida da população e a biodiversidade local.

\section{CONCLUSÕES}

Barcarena enquanto ambiente urbano amazônico nas últimas décadas tem sido destino de uma parcela significativa de empreendimentos industriais e outras atividades consorciadas que a colocam diante permanentemente de uma encruzilhada que aponta simultaneamente para o desenvolvimento e para as mazelas dos impactos sociais e ambientais. Pois sua matriz produtiva está integrada ao eixo do comércio internacional, e este elo se impõe extremamente rígido firmando um horizonte que é reflexo da lógica de produção e exploração do capital internacional.

Os impactos socioambientais emergem como substrato negativo dessa dinâmica ambivalente que se materializam nos espaços urbanos amazônicos através da perda da cobertura vegetal, poluição dos rios por rejeitos minerais e resíduos sólidos urbanos, empobrecimento e contaminação dos solos, além de um variado leque de impactos sociais adversos como marginalização social das camadas mais pobres, moradias insalubres, sistema de transporte precário, dificuldades de acesso ao sistema e esgoto e água potável que no seu conjunto negam as populações urbanas amazônicas o direito a um ambiente urbano sustentável.

Este estudo buscou levantar, descrever e analisar determinadas variáveis que expressam individual ou integradamente a qualidade ambiental urbana através de indicadores que são capazes de traduzir as condições socioambientais que esses espaços apresentam. No caso em evidência analisamos a qualidade ambiental dos Distritos do Murucupi e Vila do Conde em Barcarena, Pará, chegando à conclusão que este ambiente urbano amazônico apresenta uma qualidade ambiental considerada frágil ou ruim, isto é, as variáveis socioambientais interpretadas e analisadas através de indicadores mostraram-se deficientes, incompletas ou mesmo inexistentes.

Importa destacar que a qualidade ambiental do espaço quando se apresenta ruim os consequentes efeitos danosos à saúde ou a qualidade de vida da população são múltiplos. Podendo ser o surgimento de patologias ligadas à má qualidade da água, aos efeitos descontrolados da insolação provocados pela cobertura vegetal reduzida, a inexistência e mesmo deficiência no sistema de esgotamento sanitário, doenças psíquicas associadas à precariedade do meio físico, sentimento de infelicidade ou frustação por se habitar um recorte urbano insalubre e que não atende as necessidades dos seus moradores, ferindo seu status de cidadãos com direito ao meio ambiente sustentável, levando a um sentimento de abandono pelo poder público que parece não se importam com as necessidades e direitos da população urbe de Barcarena.

Portanto os indicadores ambientais foram mobilizados para traduzir essa realidade socioambiental 
que se circunscreve nos Distritos do Murucupi e Vila do Conde em Barcarena, Pará, e mostraram-se, enquanto instrumento metodológico, capazes de descrever e analisar as variáveis socioambientais que indicaram as condições do esgotamento sanitário, pavimentação das vias, arborização, serviço de água e coleta de resíduos sólidos e ao serem agregados dimensionaram a qualidade ambiental desses dois extratos urbanos integradamente.

Esperamos que este trabalho venha a contribuir para a leitura e interpretação da realidade socioambiental dos espaços urbanos amazônicos, a partir da realidade socioambiental dos Distritos do Murucupi e Vila do Conde, em Barcarena, e suas inúmeras instabilidades e conflitos socioambientais que afligem parcela considerável dos habitantes desta cidade da Amazônica, parte deles descritos e analisados neste trabalho. E aponte uma perspectiva possível em se traçar políticas públicas de assistência e reparação dos ambientes natural e construído, bem como políticas de assistência as populações, em especial as que se encontram em situação de vulnerabilidade ambiental e social. Além de se buscar recuperar e preservar os ecossistemas afetados pelos desastres e impactos ambientais. Estabelecendo-se de forma sólida um horizonte promissor que nos dê o vislumbre de se estabelecer não apenas uma cidade sustentável, mas sim, cidades sustentáveis socioambientalmente em solo amazônico.

\section{REFERÊNCIAS}

BARCARENA. Plano de saneamento básico municipal. serviços de abastecimento de água e de esgotamento sanitário. Barcarena, 2013.

BORGES, C. F.; MARIM, G. C.; RODRIGUES, CARDOSO, J. E.. Análise da cobertura vegetal como indicador de qualidade ambiental em áreas urbanas: um estudo de caso do bairro da Pedreira - Belém/PA. In: SEMINÁRIO IBERO AMERICANO DE GEOGRAFIA FÍSICA, 2. Anais. Universidade de Coimbra, Coimbra, 2010.

BRASIL. Vigilância e controle da qualidade da água para consumo humano. Brasília: Ministério da Saúde, 2006.

BRASIL. Lei no 12.305. Dispões sobre a Política Nacional de Resíduos Sólidos. Brasília: DOU, 2010.

BRASIL. Doenças infecciosas e parasitárias: guia de bolso. Brasília: Ministério da Saúde, 2010.

IBGE. Instituto Brasileiro de Geografia e Estatística. Atlas de saneamento 2011. Manejo de resíduos sólidos. Brasília, IBGE: 2011.

IBGE. Instituto Brasileiro de Geografia e Estatística Morbidade e Óbitos - Barcarena. IBGE: 2020.

BRASIL. Relatório de situação: Pará. Brasília: Ministério da Saúde, 2011.

IBGE. Instituto Brasileiro de Geografia e Estatística Cidades Barcarena. Brasília: IBGE, 2020.

CRISTO, A. M.; TEISSERENC, M. J. S. A.. Justiça ambiental e bem comum em questão: mineração, populações e água em Barcarena (PA). REUNIÃO BRASILEIRA DE ANTROPOLOGIA, 31. Anais. Brasília: Universidade de Brasília, 2018.
DIAS, F. A.; GOMES, L. A.; ALKMIM, J. K.. Avaliação da qualidade ambiental urbana da Bacia do Ribeirão do Lipa através de indicadores, Cuiabá/MT. Sociedade \& Natureza, v.23, n.1, p.127-147,2011. DOI: http://dx.doi.org/10.1590/S1982-45132011000100011

FEITOSA, R. C.. Uso de sistemas modulares vegetados para promoção da saúde urbana e atenuação do estresse térmico. Saúde em Debate, v.43, n.3, p.109-120, 2019. DOI: https://doi.org/10.1590/0103-11042019s308.

FUNK, C.; PETERSON, P.; LANDSFELD, M.; PEDREROS, D.; VERDIN, J.; SHUKLA, S; HUSAK, G.; ROWLAND, J.; HARRISON, L.; HOELL, A.; MICHAELSEN, J.. The climate hazards infrared precipitation with stations: new environmental record for monitoring extremes. Scientific Data, v.2, 2015.

MAGALHÃES, J.. Indicadores ambientais e recursos hídricos: realidade e perspectivas para o Brasil a partir da experiência francesa. 4 ed. Rio de Janeiro: Bertrand Brasil, 2012.

MARIN, R. E. C.; ACEVEDO, R. B. O.. Danos sociais e ambientais pela exploração mineral em Barcarena. In: MARIN, R. E. C.; NOVAES, J. S.. Povos tradicionais em colisão com estratégias empresariais no Maranhão e Pará. Belém: UEA, 2015.

MARINHO, J. S.; JESUS, I. M.; ASMUS, C. I. R. F.; LIMA, M. O.; OLIVEIRA, D. C.. Doenças infecciosas e parasitárias por veiculação hídrica e doenças respiratórias em área industrial, Norte do Brasil. Cadernos Saúde Coletiva, p.443-451, 2016. DOI: http://dx.doi.org/10.1590/1414-462X201600040120

MARQUES, F. M. F.. Estimativa da temperatura superficial e do saldo de radiação por meio do Método Sebal no entorno da fábrica de alumina da região de Barcarena utilizando 
imagens do satélite LANDSAT. Dissertação (Mestrado em Energia e Ambiente) - Universidade Federal do Maranhão, São Luís, 2014.

MARTINS, C. C.; NUNES, Patrícia Maria P. M. P.. O discurso ambiental empresarial: na trilha da devastação. In: MARIN, R. E.; NOVAES, J. S.. Povos tradicionais em colisão com estratégias empresariais no Maranhão e Pará. Belém: UEA, 2015.

MELO, F. A. C.; UENO, M.. Caracterização e modelagem de indicadores de qualidade ambiental urbana integrada e aplicação à Vila Habitacional União, bairro da Terra Firme, Belém, Pará. Revista Ambiente e Água. v.8, p.200-220, 2013. DOI: http://dx.doi.org/10.4136/ambi-agua.1372.

MPF. Ministério Público Federal. Resumo histórico de sua expansão urbana. Barcarena, 2018.

MMA. Ministério do Meio Ambiente. Programa Cidade + Verdes. Brasília, 2020.

NÓBREGA, R. S.. Impactos do desmatamento e de mudanças climáticas nos recursos Hídricos na Amazônia Ocidental utilizando o modelo SLURP. Revista Brasileira de Meteorologia, v.29, P.111-120, 2014. DOI: https://doi.org/10.1590/0102-778620130024
OMS. Planeamento da segurança do saneamento: manual para o uso e eliminação segura de águas residuais, águas cinzentas e dejetos. Lisboa, 2016.

SANTOS, S. S. M.. Capacidade institucional, gestão ambiental descentralizada e sustentabilidade: o caso de Barcarena (PA). Dissertação (Mestrado Gestão dos Recursos Naturais e Desenvolvimento Local na Amazônia) Universidade Federal do Pará, Belém, 2015.

SILVA, S. F.; HAZEU, M. T.. O complexo industrial-portuário em Barcarena e a saúde de comunidades tradicionais na Amazônia brasileira. 0 Social em Questão, V.22, n:44, p.171 $-194,2019$.

SILVA, C. N.; REIS, J. F. G.; SILVA, J. M. P.; PORTO, J. L. R.; LIMA, R. Â. P.. Uso do território e implicações socioterritoriais da mineração no Município de Barcarena (Pará - Brasil): População, arrecadação e segurança pública. Revista Espacios, v.38, n.6. p.24-41, 2017.

SERVA, M.; JAIME JÚNIOR, P.. Observação participante e pesquisa em administração: uma postura antropológica. Revista de Administração de Empresas, v.35, n.1, p.64-79. 1995. DOI:

https://doi.org/10.1590/\$003475901995000300008 